\title{
Marco Zero: da crise à violência fundadora do estado distópico
}

DOI: https://doi.org/10.22409/pragmatizes.v10i18.38766

\section{Pedro Sasse $^{1}$}

\begin{abstract}
Resumo: Um dos nomes mais conhecidos da ficção distópica brasileira é, sem dúvida, Ignácio de Loyola Brandão, através de Não verás país nenhum, publicado em plena ditadura militar. Recentemente, o autor retornou ao gênero da distopia através de Desta terra nada vai sobrar, a não ser o vento que sopra sobre ela, revelando nessa escolha o sintoma de certo clima político que, longe de se limitar ao território nacional, se une a manifestações internacionais como a recente série distópica produzida pela BBC, Years and Years, e The Testments,uma inesperada continuação da mais famosa distopia de Atwood, $O$ conto da aia. Com a publicação de sua nova distopia, Brandão identifica o encerramento de uma trilogia que tem como primeiro romance Zero. Diferente dos outros dois, Zero não é, no entanto, associado à ficção distópica, mas geralmente tomado como uma sátira política ao período da ditadura, tendo sido, inclusive, censurado na época de seu lançamento. Partindo da associação com as demais obras que compõem a trilogia de Brandão, o presente trabalho se propõe a ler o romance Zero não pelo viés de suas abordagens usuais, mas tomá-lo como objeto dentro da tradição distópica, entendendo-o como uma representação do momento de transição entre o presente de crise e o futuro sombrio que o substitui, transição essa marcada por uma violência fundadora tanto física quanto política.
\end{abstract}

Palavras-chave: Ditadura; distopia; tempo; violência; totalitarismo.

\section{Zona Zero: de la crisis a la violencia fundadora del estado distópico}

Resumen: Uno de los nombres más conocidos de la ficción distópica brasileña es, sin dudas, Ignácio de Loyola Brandão, mediante Não verás país nenhum, publicado en plena dictadura militar. Recientemente, el autor ha retornado al género de la distopia con Desta terra nada vai sobrar, a não ser o vento que sopra sobre ela, revelando en esa elección un síntoma de cierto clima político que no se limita al territorio nacional, pero se une a manifestaciones internacionales como la reciente serie distópica produzida por la BBC, Years and Years, y Los testamentos, una inesperada continuación para la más famosa distopia de Atwood, El cuento de la criada. Con la publicación de su nueva distopia, Brandão identifica el encerramiento de una trilogía que tiene como primera novela Zero. Diferente de las otras dos, Zero no es, sin embargo, asociada a la ficción distópica, pero normalmente tomada como una sátira política al período de la dictadura, habiendo sido, incluso, censurada en la época de su publicación. Partiendo de la asociación con las demás obras que componen la trilogía de Brandão, este trabajo se propone a leer Zero no por su abordaje usual, pero como un objeto dentro de la tradición distópica, entendiéndolo así como una representación del momento de transición entre un presente de crisis y el futuro sombrío que lo sustituye, transición esa marcada por una violencia fundadora, tanto física cuando política.

Palabras clave: Dictadura; distopia; tiempo; violencia; totalitarismo.

\footnotetext{
${ }^{1}$ Pedro Puro Sasse da Silva. Doutor em Estudos de Literatura pela Universidade Federal Fluminense (UFF). Professor convidado do Programa de Pós-Graduação em Estudos de Literatura da UFF, Brasil. E-mail: pedro_sasse@hotmail.com - ORCID: https://orcid.org/0000-0001-7441-7122.
}

Texto recebido em 21/11/2019 e aceito para publicação em 04/01/2020. 
Ground Zero: from the crisis to the founding violence of the dystopian state

\begin{abstract}
One of the most notorious names of the Brazilian dystopian fiction is, without doubt, Ignácio de Loyola Brandão, through Não verás país nenhum [1981], published during the military dictatorship. Recently, the author returned to the dystopian genre through Desta terra nada vai sobrar, a não ser o vento que sopra sobre ela [2018], revealing in this choice the symptom of a political atmosphere that rather than being limited by national boundaries - joins other international manifestations such as the recent dystopian BBC series Years and Years and The Testments, an unexpected sequel for the most famous of Atwood's dystopias, The Handmaid's Tale. With the publication of his new dystopia, Brandão identifies the ending of a trilogy started with the novel Zero. Different from the others, Zero is not, however, associated with dystopian fiction but, instead, more commonly considered a political satire of the dictatorship era - which lead to it being censored. With an assumption of the association with the dystopian novels that form the trilogy, this work aims to read Zero not by the common approaches, but rather as within the dystopian tradition, understanding it as a representation of the transition between a present crisis and a dark future that replaces it - with a transition marked both by political and physical violence.
\end{abstract}

Keywords: Dictatorship; dystopia; time; violence; totalitarianism.

\title{
Marco Zero: da crise à violência fundadora do estado distópico
}

"Se você quer formar uma imagem do futuro, imagine uma bota pisoteando um rosto humano - para sempre" (ORWELL, 2009, p. 312). Através das palavras do personagem O’Brien, Orwell deixa cristalizado no imaginário de seus leitores mais do que uma imagem de opressão, deixa um símbolo que condensa em si a poética do gênero que sua obra ajuda a delinear, a ficção distópica. Através dessa imagem, entendemos que a distopia é, sobretudo, uma representação da opressão - violenta - de um estado absoluto sobre o povo. Sucedendo precursores do gênero como Nós [1924], de Yevgeny Zamyatin, 1984 [1949], de George Orwell, ao lado de Admirável mundo novo [1932], de Aldous Huxley, consolida um gênero em plena sintonia com os horrores políticos produzidos ao longo do século $X X$ - pelos projetos totalitários, de um lado, e pelo capitalismo desenfreado, do outro.

No Brasil, ainda que a recepção de Orwell tenha se dado pouco tempo após a publicação de 1984, apenas na década de 70 a política interna do país cria o cenário favorável para o florescimento desse tipo de ficção. $O$ clima de censura, vigilância e violência instaurado pela ditadura militar alimentará um período pródigo na produção de obras nacionais com inclinações distópicas, dentre as quais podemos destacar Adaptação do funcionário Ruam [1975], de Mauro 
Chaves, $O$ fruto do vosso ventre [1976], de Herberto Sales, e, uma das mais conhecidas, Não verás país nenhum [1981], de Ignácio de Loyola Brandão.

Enquanto o Brasil dava seus primeiros passos firmes nessa literatura distópica totalitária, a literatura anglófona já começa, a partir do fim da segunda guerra mundial, a distanciar-se desse modelo, conforme os próprios projetos totalitários europeus vão perdendo força. Novas ansiedades surgem e a bota esmagando o rosto humano deixa de estar no horizonte de expectativa de autores e leitores, sendo substituída por temores como: (i) a partir da década de 1950, a destruição do planeta em uma guerra nuclear; (ii) a partir da década de 1970, a degradação ambiental levando a uma catástrofe climática sem precedentes; (iii) uma progressiva mecanização da sociedade e subordinação do homem à tecnologia, levando a um apagamento das fronteiras identitárias humano/máquina; (iv) e a expansão das sociedades de consumo e a produção de massas alienadas, cultural e intelectualmente prostradas aos padrões hedonistas de vida vendidos pela mídia (cf. CLAEYS, 2017, p.447).

Nos aproximamos, assim, do século XXI com uma crescente confiança na superação do pesadelo orwelliano. Por mais que a distopia houvesse rapidamente encontrado novos caminhos para traçar sua projeção negativa do futuro, cada vez menos a metáfora de O'Brien dialogava com as tensões do presente.

Tal confiança foi, hoje percebemos, falsa: nos últimos anos, uma onda conservadora se alastrou por países da Europa e das Américas. Políticos de extrema direita sobem ao poder, com discursos perigosos envolvendo nacionalismo, moral e religião, infundindo medo para justificar atos extremos; grupos neonazistas saem à luz do dia em marchas carregadas de xenofobia; a hostilidade cresce contra imigrantes, refugiados e rapidamente se alastra a outras minorias. Em 2018, o escritor Daniel Olivas, em uma coluna para o The New York Times, conclui, diante de uma das ações desumanas do governo Trump, que "A distopia está aqui”:

Eu queria que minha história servisse como um conto de advertência sobre o que nosso país poderia se tornar caso as políticas 
imigratórias do Sr. Trump fossem totalmente concretizadas. Mas agora é a nossa realidade: filhos e filhas estão sendo arrancados dos braços de seus pais - em alguns casos literalmente - e centros de detenção estão ficando cheios de crianças apavoradas. Em comunidades imigrantes, o medo é palpável, com pais se perguntando se eles deveriam arriscar levar seus filhos à escola ou ir trabalhar ou denunciar um crime, temendo se tornarem vulneráveis a uma batida dos agentes da imigração. ${ }^{2}$ (OLIVAS, 2018. Tradução própria)

No ano anterior, a Hulu lança uma adaptação televisiva da assustadora distopia de Margaret Atwood, O conto da aia [1985], uma das narrativas distópicas que ainda apelava para a distopia totalitária na segunda metade do século $X X$, explorando os perigos da exploração do moralismo como ferramenta política, o fundamentalismo religioso e o controle dos corpos pelo Estado. Se a própria autora, na posterior trilogia pós-apocalíptica Madd Addam, havia se voltado para os temas distópicos

\footnotetext{
${ }^{2}$ No original: "I wanted my story to serve as a cautionary tale of what our country could devolve into if Mr. Trump's immigration policies were fully realized. But now this is our reality: Sons and daughters are being ripped from their parents' arms - in some cases, literally - and detention centers are filled with frightened children. In immigrant communities, the fear is palpable, with parents asking themselves if they should risk taking their children to school, or going to work or reporting a crime, lest they become vulnerable to a sweep by immigration agents".
}

pós-totalitários que anteriormente citamos, o lançamento súbito de uma continuação para $O$ conto da aia - Os testamentos [2019] - mostra que Atwood percebe 0 retorno do totalitarismo como ameaça em uma visão distópica do futuro.

No Brasil, acompanhando quase o mesmo intervalo de produção das distopias totalitárias de Atwood, Ignácio de Loyola Brandão Iança, também em 2019, uma nova visão distópica do Brasil, Desta terra nada vai sobrar a não ser o vento que sopra sobre ela (doravante Desta terra...), encerrando o que o autor considera ser uma trilogia que iniciaria com Zero [1974]. Se as duas últimas obras dessa trilogia são facilmente reconhecíveis como distopias, Zero, no entanto, é mais resistente a uma classificação de tal tipo. Romance experimental, fragmentado, construído através de diversos gêneros textuais distintos, oscilando de um realismo cru ao surrealismo, Zero foge ao molde mais tradicional dos romances distópicos.

Se nossa introdução nos levaria, de forma mais natural, a propor uma leitura de Desta terra... que ressaltasse 0 diálogo com 0 
cenário local e global da ascensão desse novo totalitarismo, desejamos, na verdade, diante da nova produção de Loyola Brandão e do atual cenário de novo fôlego das distopias totalitárias, retornar ao romance Zero para ler nele não a imagem de uma distopia estabelecida, mas para tomálo como uma narrativa da violência fundadora do estado distópico, uma espécie de origem, marco zero, da guinada social que marca a ascensão de um regime opressivo, controlador e violento, que vemos de forma já consolidada nos romances distópicos tradicionais.

Tal leitura se vê, ainda, incentivada por uma peculiar produção distópica contemporânea: a recente série da BBC OneYears and Years [2019]. Sucesso de audiência e crítica, a série vem reforçar esse retorno da distopia totalitária ao pensamento contemporâneo, mas de uma forma atípica: distinguindo-se de obras como Nós, 1984 e O conto da aia, Years and Years não é situado em um futuro em que um regime já detém o pleno controle da sociedade, mas, tomando como ponto de partida o nosso presente, mostra, ano a ano, como o título sugere, os eventos que culminarão na fundação desse estado distópico.

Years and Years não é um aviso sobre o que podemos nos tornar num futuro muito distante. É um documentário satírico sobre nosso presente, tomando a projeção no futuro imediato apenas para afinar essa caricatura de nossos tempos. Nossa hipótese é que Zero, mesmo que afastado pelo próprio Loyola do escopo de sua produção distópica, é também essa espécie de distopia em processo. Se controle é uma palavrachave para entender a distopia tradicional, nesse estágio ainda embrionário de formação do estado distópico, a violência será o tema central: violência política no processo progressivo de perda dos direitos constitucionais; violência cognitiva na drástica mudança de visão de mundo trazida pela implementação de um novo sistema; e, sobretudo, violência física, direta e explícita, no confronto entre o Estado totalitário que começa a se estabelecer e a resistência que precisa ser esmada para que sobre os seus corpos seja erguida a verdadeira distopia. 


\section{Do marco zero ao fim do tempo}

Para podermos fazer uma análise de Zero a partir da ótica da distopia, é preciso, antes, desdobrar essa hipótese daquilo que chamamos de estágio pré-distópico encontrado na obra de Loyola, na série Years and Years e, se quisermos um exemplo dentro do próprio cânone distópico, Laranja mecânica [1962], de Anthony Burgess.

A distopia mantém uma relação complexa com o tempo, tanto diegético quanto cronológico. O próprio conceito distopia já nasce, de certa forma, anacrônico para designar o que hoje entendemos pelo gênero. Esse lugar apontado pelo sufixo de distopia topos - remete ao neologismo de More em sua fundadora Utopia que, posteriormente, num jogo de sátira, crítica e negação, possibilitará o surgimento tanto do gênero quanto do termo derivados.

More formula o nome de sua ilha através do prefixo de negação $-u$, criando um não-lugar, ou um lugar outro, um lugar além de nossa visão de mundo. Esse lugar, na obra de Morus (assim como posteriormente vemos em Bacon ou Campanella) era contemporâneo ao contexto de produção da obra, uma espécie de sociedade isolada, ainda não descoberta. Dessa forma, o tempo ainda não era um elemento central para o gênero como mais tarde se tornará.

As utopias de More, Campanella ou Bacon são fruto de uma visão de mundo anterior à noção de progresso e de história que se fundará a partir do pensamento iluminista no século XVIII:

A projeção dos desejos utópicos no futuro implicou uma mudança na própria natureza da utopia - e assim nasceu uma derivação neologística. Da eu/utopia, o bom/não-lugar, nos movemos para a eucronia, o lugar bom no futuro. O nascimento da eucronia se dá por uma mudança na mentalidade, presidida por uma visão de mundo otimista que prevaleceu na Europa no lluminismo. $\mathrm{Na}$ Renascença, o homem havia descoberto que havia opções alternativas à sociedade em que ele vivia, tornara-se consciente dos poderes infinitos da razão e entendera que a construção do futuro estava em suas mãos. No lluminismo, o homem descobriu que a razão the possibilitaria não apenas a ter uma vida feliz, mas a alcançar a perfeição humana. A Utopia de More é o resultado da descoberta que ocorre na Renascença; eucronia é o produto da nova lógica do lluminismo. ${ }^{3}$ (VIEIRA, 2010, p. 9. Tradução própria).

\footnotetext{
${ }^{3}$ No original: "The projection of the utopian wishes into the future implied a change in the very nature of utopia - and thus a derivation neologism was born. From eu/utopia, the $\mathrm{good} /$ non-place, we move to euchronia, the good place in the future. The birth of euchronia was due to a change of mentality, presided over by the optimistic worldview that prevailed
} 


\author{
pragMaTMES \\ www.periodicos.uff.br/pragmatizes - ISSN 2237-1508 \\ (Dossiê "Representações da Violência na Literatura") \\ projetivas. ${ }^{4}$ (VIEIRA, 2010, p. 17. \\ Tradução e grifos próprios)
}

A mudança da projeção dessa sociedade imaginada do espaço para o tempo não encontrará, no entanto, equivalência numa atualização taxonômica, e usos de ucronia, ainda que mais precisos, só encontrarão lugar em alguns poucos críticos especializados no gênero. A literatura distópica, ainda que tenha dado se consolidado como gênero apenas no século $X X$ - e desde o início estivesse atrelada a essa projeção no tempo mais que no espaço - manteve o paralelo com o gênero do qual deriva. Tal descompasso etimológico acabará gerando algumas contradições:

\begin{abstract}
A distopia literária usa os dispositivos narrativos da utopia literária, incorporando em sua lógica os princípios da eucronia (ou seja, imaginando como o mesmo lugar - o lugar em que o utopistavive - será em outro tempo - no futuro), mas prevê que as coisas sairão mal; é, portanto, essencialmente pessimista em sua apresentação das imagens
\end{abstract}

in Europe in the Enlightenment. In the Renaissance, man discovered that there were alternative options to the society he lived in, became aware of the infinite powers of reason and understood that the construction of the future was in his hands. In the Enlightenment, man discovered that reason could enable him not only to have a happy life, but also to reach human perfection. More's Utopia is the result of the discovery that occurred in the Renaissance; euchronia is the product of the new logic of the Enlightenment".
Percebamos que se aponta o uso da utopia e chama-se de utopista o produtor dessas narrativas distópicas, ainda que a lógica utilizada seja etimologicamente oposta à ideia de utopia, uma vez que apresenta não esse outro lugar significado pela utopia, mas justamente "o mesmo lugar". Caso se buscasse priorizar a precisão conceitual à popularização do termo, discronia seria mais apropriado, uma vez que o eixo de deslocamento nesse gênero é o tempo, e não mais o espaço. No entanto, dada a popularização de distopia e seu vasto uso mesmo entre os especialistas, mantém-se, assim o conceito de distopia, ainda que problemático.

Sendo, então, característico da distopia seu deslocamento temporal em relação ao presente de seu contexto de produção - criando nesse deslocamento uma projeção negativa do futuro -, nos interessa observar não

\footnotetext{
${ }^{4}$ No original "Literary dystopia utilizes the narrative devices of literary utopia, incorporating into its logic the principles of euchronia (i.e., imagining what the same place - the place where the utopist lives - will be like in another time - the future), but predicts that things will turn out badly; it is thus essentially pessimistic in its presentation of projective images".
} 
apenas 0 ponto inicial - presente, contexto de produção da obra - e final - futuro negativo estabelecido - dessa trajetória, mas entender os estágios intermediários desse processo, dados apenas entrevistos das distopias totalitárias canônicas.

Observando romances basilares para pensar a distopia, como Nós, 1984, Admirável mundo novo, Fahrenheit 451, de Ray Bradbury, e 0 conto da aia, é possível perceber certas constâncias no uso do tempo e na construção do espaço narrativo. Em todos esses casos, somos apresentados já a uma sociedade em que 0 estado distópico se vê plenamente estabelecido: uma nova lógica de mundo - em que a liberdade cede espaço ao controle, em que a coletividade substitui a individualidade, e uma tecnocracia autoritária substitui a democracia - já é tomada como natural para a maior parte da população e suas estratégias de controle e vigilância já estão integralmente implementadas.

Em uma primeira análise, Laranja mecânica, geralmente associado a essas distopias literárias de grande circulação e atenção crítica - sobretudo após o bem sucedido filme de Kubrik baseado na obra de Burgess -, parece resistir a essa definição se buscamos na obra os mesmos temas que encontramos nos romances distópicos anteriormente citados: não há governo totalitário controlando cada aspecto da vida de sua população, não há coletividade compulsória, paranoia, manipulação completa da informação. A sociedade em que vive Alex, o protagonista do romance, não é a nossa, sem dúvida. Não compartilhamos sequer o idioma com os personagens dessa sociedade. No entanto, ela é consideravelmente mais próxima da lógica de funcionamento da nossa sociedade do que aquela encontrada na Oceânia ou em Gilead, por exemplo. A diferença do mundo de Burgess para o nosso é apenas uma questão de intensidade jovens mais violentos, caos urbano mais generalizado, degeneração moral mais explícita. De fato, o único ponto de contato, talvez, entre Laranja mecânica e as distopias totalitárias se dê no pano de fundo político da obra, que só ganha foco narrativo através da Técnica Ludovico, método de lavagem cerebral construído para impedir que criminosos voltem a praticar delitos. 
Utilizando a tecnologia para

fundo da obra. Tendo como foco retirar a vontade do homem, castrando-o da possibilidade de cometer atos violentos, a técnica, ainda experimental, se aproxima dos mecanismos de controle do estado distópico. A Técnica Ludovico está, contudo, longe de ser uma prática naturalizada dentro da sociedade de Laranja mecânica. Ao compará-la com - controle comportamental da humanidade através da tecnologia que vemos em Admirável mundo novo, por exemplo, - via redução dos níveis de oxigênio nos fetos, lavagem cerebral hipnopédica e a droga calmante Soma -, temos como diferença o fato de que, na sociedade de Alex, esse controle é excepcional - o rapaz é o primeiro paciente - e encontra pronta resistência - que em última instância será responsável por frear o avanço do partido totalitário -, enquanto na sociedade de Bernard Marx, o processo é a regra, implementada em toda a população e tomada como natural pela quase totalidade de seus cidadãos.

O estágio inicial da Técnica Ludovico serve de metonímia para o próprio estágio de formação do estado totalitário que se esboça no pano de

narrativo Alex, um adolescente alienado, não temos acesso a muito mais do que sua rotina de violência e, posteriormente, sua vida na prisão. Os únicos momentos em que podemos vislumbrar com clareza o contexto político de Laranja mecânica é em alguns diálogos de Alex, sobretudo com os membros do partido de oposição, responsáveis por acolhê-lo inicialmente após a lavagem cerebral. F. Alexander, escritor e vítima prévia do rapaz - ainda sem reconhecer seu agressor -, é o primeiro a ajudá-lo, ficando escandalizado com o processo a que o menino foi exposto. Ao mesmo tempo, vê, junto com os demais membros do partido, a possibilidade de derrotar o governo autoritário que crescia explorando o caso trágico de Alex:

- (...) Acho que você pode ajudar a desalojar esse governo super exigente. Transformar um jovem decente em uma coisa mecânica não deveria, certamente, ser encarado como triunfo para nenhum governo, a não ser aquele que se gabe de sua capacidade de repressão (BURGESS, 2014, p. 156-7).

- (...) Sabe, aquilo de que o governo mais se gaba é a maneira pela qual lidou com o crime nestes últimos meses. (...) Recrutando jovens brutos para a polícia. Propondo técnicas de condicionamento debilitantes e que tiram a força de vontade. (...) Já vimos tudo isso antes - ele disse - em outros países. 
Estamos à beira do abismo. Sem que nos apercebamos, daqui a pouco teremos o aparato completo do totalitarismo (p. 160)

O que temos no caso de Laranja mecânica, então, é um governo em vias de tornar-se totalitário, experimentando suas primeiras medidas de controle da população, a princípio em cidadãos desamparados pela lei e despojados da possibilidade de luta. O grupo de F. Alexander serve para marcar a resistência aberta de uma parcela da sociedade - intelectual, humanista e defensora das liberdades individuais como são geralmente os dissidentes do estado totalitário distópico - ao regime ainda democrático que ganha ares de totalitarismo.

Longe de um final esperançoso, a tentativa de usar Alex contra o governo falha diante de outra estratégia do totalitarismo: o controle da informação. Após uma tentativa de suicídio do rapaz induzida por $F$. Alexander, que havia descoberto que Alex era um dos responsáveis pelo estupro e morte de sua esposa, o Ministro do Interior repara os danos feitos ao rapaz e, numa jogada de publicidade, usa os jornais para mudar a opinião pública diante do caso.
Assim, ainda que a obra se encerre pouco depois, temos a sugestão de que esse governo autoritário continua a crescer, esboçando um caminho claro em direção ao estado distópico.

Diante dessa tensão entre governo democrático autoritário e o esboço de uma distopia totalitária projetada para o futuro, podemos tomar a organização política de Laranja mecânica como o primeiro estágio de desenvolvimento de um estado distópico. Estamos, claramente, diante de um cenário distinto do contemporâneo, mas apenas em grau, mantendo uma mesma lógica de funcionamento das organizações sociais e políticas.

Esses estágios anteriores à consolidação do estado distópico, em alguns casos, podem ser vislumbrados também nas distopias plenas através de investigação histórica, conversa com sobreviventes ou flashbacks. No entanto, são informações geralmente obstruídas pelo contínuo processo de manipulação da informação e apagamento/reformulação da história e da memória operado pelo governo - 0 Ministério da Verdade em 1984, a queima dos livros em Fahrenheit 451, 
a proibição da leitura em $O$ conto da aia etc.

Vale ressaltar que tais informações são mais ou menos acessíveis dependendo do ponto cronológico escolhido para o presente narrativo nas distopias estabelecidas. Em $O$ conto da aia, ainda que não haja um acesso livre à informação, o foco é a primeira geração do estado distópico; todos seus membros viveram o tempo de transição, permitindo, como vemos, a exploração desse estágio pré-distópico através da memória da própria protagonista. Em Fahrenheit 451, Guy já não pertence a geração que viveu o momento de transição, mas tal geração está viva, como vemos em seu diálogo com Faber, o velho professor. Já em Admirável mundo novo, o presente narrativo está centenas de anos no futuro, e o único acesso a esse passado de transição é através de registros - e, de alguma forma, através da preservação cultural de grupos como aquele de que vem John.

Analisando as relações dessas distopias com o tempo, a implementação de seus governos e os vestígios do passado apresentados, sugerimos estabelecer uma cronologia dos estágios de desenvolvimento de uma distopia da seguinte forma:

1- Presente: o presente de produção da obra é o ponto de partida. Sendo o único ponto de coincidência cronológica entre a narrativa distópica e seu contexto de recepção inicial, esse presente é visto de forma ambivalente: ressalta-se 0 aspecto negativo do presente, vendo-o como um momento de crise (política, econômica, ecológica, moral, intelectual etc.), mas tal destaque tem, em geral, uma função crítica $e$ conscientizadora, um impulso de esperança na resolução dessa crise antes que a terrível predição distópica se concretize.

2- Totalitarismo velado: esse estágio inicial de crise se intensifica até o ponto de se tornar intolerável. Grupos totalitários se aproveitam do descontentamento da população e justificam medidas drásticas, negociando ideais democráticos, direitos humanos e liberdades individuais em troca de uma solução eficaz para a crise. Essa é, ainda, uma fase mais de 


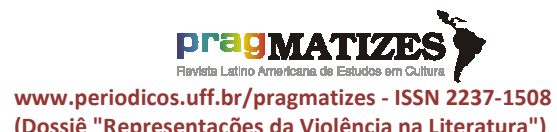

(Dossiê "Representações da Violência na Literatura") adesão que de imposição dos ideais distópicos. É o momento em que a população, iludida, apoia tais grupos diante dos resultados obtidos - ou apenas anunciados - no combate à crise, como vemos na reação favorável do público ao governo em Laranja mecânica.

3- Violência fundadora: 0 poder investido nesse grupo totalitário cresce ao ponto em que não é preciso mais sustentar as vias democráticas. Dessa forma, inicia-se o processo de consolidação dos mecanismos de controle da população. Nessa drástica mudança no funcionamento da sociedade, muitas das características presentes na distopia estabelecida já são implementadas em larga escala, diferente do estágio anterior. No entanto, o que diferencia esse momento do estágio final de desenvolvimento do estado distópico é a presença de uma resistência

a essa implementação. Um ou mais grupos se erguem como voz dissonante e lutam contra as mudanças, confronto que leva ou a um impedimento da ascensão do poder totalitário ou a uma derrota e extermínio dos opositores.

4- Distopia estabelecida: Após 0 silenciamento de qualquer voz ativamente divergente, os processos se naturalizam, a população é eficazmente controlada através da docilização e da vigilância, e os vestígios da violência fundadora, apagados, num gesto que tenta justamente desconectar a distopia do tempo, tornando-a, assim, eterna.

Claro que, como qualquer esquema, o acima proposto pode esbarrar com exceções, como distopias em que a transição ao novo modelo é alcançada sem uma resistência declarada. Ainda nesses casos, no entanto, resta, se não uma violência física contra opositores, uma violência política no cerceamento da liberdade, na imposição da coletividade, no aparato de vigilância e controle etc.

Um ótimo exemplo da trajetória de formação desse Estado distópico 
se dá na recente série lançada pela BBC One Years and Years, de Russel T. Davies. Diante de um crescente clima de totalitarismo que retorna ao pensamento contemporâneo - como vimos intuído no texto de Olivas -, Davies propõe não uma distopia, mas a história de formação de uma distopia, justamente essa história que se tenta - e muitas vezes se consegue - apagar durante o processo de consolidação do governo totalitário e que só nos chega, geralmente, através de vestígios.

A série toma como ponto de partida a contemporaneidade, criando um marco inicial no nascimento do mais novo membro da família Lyons, em Manchester. O surgimento de uma nova geração espelha 0 início da cronologia a caminho da distopia: as cenas do parto da criança são alternadas com a primeira aparição de Vivienne Rook, espécie de versão britânica de políticos como Trump e Bolsonaro. Como eles, Rook fala o que pensa, ignora o decoro esperado de um político, é sensacionalista e polêmica. Como eles, Rook se torna rapidamente a projeção do cidadão médio, insatisfeito com o sistema, frustrado com os rumos de uma democracia em decadência, cansado da demagogia da velha política. Como eles, Rook é a primeira a explorar o potencial das redes sociais, a entender que visibilidade é mais importante que preparo, que verdade ou fato são palavras obsoletas na era da instantânea difusão de mensagens.

A sequência do nascimento de Lincoln - cujo nome marca o ideal de liberdade em oposição à tirania de seu gêmeo maligno, o projeto de Rook -, ambientada ainda no presente, termina com um questionamento de seu tio: como será o mundo para aquela criança nos anos vindouros, diante da crise que já era vista no próprio presente? Tomando tal questionamento como fundamento, a série passa a narrar, ano a ano, a ascensão de Rook - que passa de piada nas redes a líder de um novo governo totalitário na Inglaterra - e a inversamente proporcional queda da família Lyons e seu engajamento na luta contra esse sistema autoritário.

Uma vez que é ambientada nos anos imediatamente posteriores ao presente de sua produção, Years and Years, assim como Laranja mecânica, se distancia de seu contexto de produção apenas pela intensidade de 
sua crise. Ainda que pequenos fazendo uma leitura à revelia da crítica avanços tecnológicos apareçam na narrativa, os problemas levantados nela são aqueles que já vivemos, apenas distorcidos pela - tênue hipérbole satírica própria do gênero distópico. De fato, para um morador dos EUA de Trump ou do Brasil de Bolsonaro, o começo da série e seus anos iniciais estão aquém da realidade já vivida nesses países. Tal fato acaba dificultando o encaixe dessas obras numa visão mais restrita de distopia, que apenas aceita o modelo totalitário em estágio final como possibilidade. Sem entrar na problemática conceitual, vale pensar nessas obras, se não como distopias, ao menos como distopias em potência, fundamentais para explorar certas questões que, nas distopias plenas, são secundárias, dentre elas, justamente, essa violência fundadora do Estado distópico.

A visão de Loyola do gênero distópico parece se alinhar a essa perspectiva mais restrita, o que o leva - ainda que aceite Zero, Não verás país nenhum e Desta terra... como uma trilogia - a distinguir Zero de suas obras distópicas, entendendo-o como um romance que fala especificamente sobre a ditadura militar. No entanto,

tradicional e da designação autoral, há em Zero justamente a hipérbole satírica que caracteriza esse cenário da crise do presente intensificada como vemos em Laranja mecânica e Years and Years. A obra de Brandão fala sobre a ditadura, mas não usa os registros realistas para tal, o faz através de um registro que nos permite aproximar o romance dessa tradição das distopias em potencial. Ainda que fale sobre o presente, o caráter preditivo fica marcado na primeira página de Zero, que expõe, ocupando a página inteira, o espaço-tempo da narrativa: "Num país da América Latíndia, amanhã" (BRANDÃO, 1979, p. 9).

\section{Trajetória da violência}

Zero é uma obra de difícil categorização. Desde já é preciso ressaltar que, diferente dos casos de Laranja mecânica e Years and Years, não se trata de obra facilmente associável ao gênero distópico. Romance experimetal, Zero tem uma narrativa fragmentada, contada através de gêneros textuais diversos, desde 0 fluxo de consciência à propaganda, utilizando ainda 
desenhos, explorando de forma não linear o espaço branco da página, criando colunas e notas de rodapé. A obra não é apenas experimental em sua forma: o conteúdo também oscila dos registros realistas ao pleno surrealismo, explorando, muitas vezes, um absurdo de influência kafkiana.

Zero é, acima de tudo, um romance sobre a ditadura militar. É escrito, no entanto, bem fora de um gênero que se espera para abordar o tema: demasiado absurdo para 0 realismo documental, demasiado realista para uma alegoria que escapasse da censura - de fato, não escapou. Mas é justamente esse tom satírico, absurdo ma non troppo, que nos permite uma leitura à revelia da crítica tradicional sobre a obra: tomando esse "amanhã" exposto na primeira página e a hipérbole da crise social retratada por Zero, podemos ver o romance como uma distopia em construção, tal como encontramos no romance de Burgess e na série da BBC.

Apesar das sequências menores que vão se desencadeando ao longo da obra, pode-se dizer que a história central é focada no personagem José, contando, por um lado, sua trajetória de matador de ratos num cinema a guerrilheiro procurado pelo governo e, por outro, o desenvolvimento de um complicado relacionamento com Rosa. A partir de tal história, com o suporte dos textos menores, vamos conhecendo essa América Latíndia, paródia sombria do Brasil da década de 70 apenas por um gesto de magnificação: mais violenta, consumista, doente, caótica.

Esse espaço, no entanto, não é dado de forma linear, mas precisa ser montado através dos fragmentos espalhados pela obra, seja nos trechos isolados ou na narrativa de José. Como vimos anteriormente, essas distopias em potência se diferenciariam das plenas distopias pela presença, ainda, da crise que justificará a ascensão do regime totalitário e da violência decorrente da resistência no processo de consolidação desse regime. Dessa forma, o primeiro elemento a se ressaltar na construção do espaço de Zero é justamente o caos social que o governo tenta combater através de suas medidas autoritárias.

Um dos problemas mais explícitos e marcantes da América Latíndia é a crise econômica em que 
se vive. Ainda nas primeiras páginas da obra vemos o nível do problema:

José foi intimado a depor. O dono da pensão se atirara ao poço, alegando miséria. Tinha convidado a mulher, mas ela não quis, disse: Vai sozinho. A polícia suspeitava. Numa só semana, três pessoas tinham se atirado em poços, alegando miséria (BRANDÃO, 1979, p. 15).

Tal problema, num mundo globalizado, é ainda intensificado pelas ondas migratórias em busca de emprego. Sem amparo social, a mão de obra estrangeira aceita salários ainda mais baixos e condições de trabalho deploráveis:

Todos os dias chegam trabalhadores à procura de emprego. Sempre há vagas nas obras dos Monumentos Nacionais. Dizem (não se confirma) que quase todos os dias morre (SIC) operários em acidente, pela falta de segurança e pela pressa com que o governo pretende terminar a obra, a fim de comemorar o Décimo Aniversário da Revolução que tirou o país das mãos dos comunistas.

$\mathrm{O}$ costarriquenho conseguiu 0 emprego, porque aceitou 0 Terço mínimo.

É isso, meu caro, se quiser. É o salário para estrangeiro. Está baixando muito em nosso país, ultimamente. ? O que é que há por lá. $^{5}$

Terço mínimo: uma das três partes do salário mínimo (BRANDÃO, 1979, p. 51-52).

Tal situação, intensificada por uma falta de interesse do governo em resolver

\footnotetext{
${ }^{5}$ A pontuação no começo das frases é uma marca estilística usada na maior parte dos fragmentos de José na obra.
}

de fato o problema - uma vez que seu foco é o combate aos revolucionários, repressão dos descontentes e uma fiscalização de questões morais -, chega, em meados da obra, à beira de um colapso social:

Esmolas, mendigos, fome, vendedores ambulantes surgindo por toda a parte. Advogados bem falantes vendendo io-iôs luminosos, ratinhos de corda, barbatana, esferográficas ( 3 por mil), saquinhos de limão (I dúzia por 50 centavos), imagens de santo, bolas de gás, isqueiros, doces feitos em casa, perfumes, livros clandestinos, chaveiros, meias, anéis, óculos, distintivos, caleidoscópios, aparelhinho de descascar batatas, réguas, lápis, borracha. Médicos vendendo flâmulas de porta em porta. Agrônomos lavando vidros de carros nos estacionamentos. Arquitetos orientando construção de barracos nas favelas.

As filas no serviço social, crescendo. Brigas todas as noites diante dos albergues, debaixo dos viadutos, pontes, nas portas de prédio, portas de igreja / os mais fortes tomando o lugar e vendendo aos mais fracos por um cigarro, um dar a bunda, uma pinga e os padres surgindo com a polícia: fora, fora da casa de deus, ó vendilhões /, um lugar para dormir.

Mendigos, vagabundos, desempregados, hordas revirando os lixos da cidade, de todas as cidades. As casas invadidas, ladrões presos ao roubar despensas, armazéns e supermercados protegidos por contigentes (SIC) policiais. Todo mundo querendo ir para a cadeia onde, ao menos, não se morre de fome.

Casal que pastava nas margens do riacho atacou a dentadas companheiros de pastagem.

Empregados demitidos. E demitidos matando patrões.

Os padres rezando e pedindo: Filhos meus, confiem em Deus e deus vos alimentará (BRANDÃO, 1979, p. 133). 


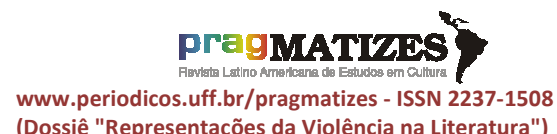

(Dossiê "Representações da Violência na Literatura")

- Era de noite. Amarramos ele no chão do pomar, perto das laranjeiras. Passamos ketchup no corpo inteiro dele e esperamos. De manhã, estava cheio de saúvas comendo ele, aaaaaaaaahhhhh, aha, ah, h, h, aha. . Ah, ah, ah, ah, ah, aaaaaaaaaaaa . Aha, aha, hahahahaaaaahahahaha . Oh, 00000000000, oh, ohoho, hohoohoooi

luiuiuiuiuiuuuuuuuuuu, uhuhii (BRANDÃO, 1979, p. 80)

de diversas formas, desde um condensado fragmento estatístico indicando números de roubos a bancos no país (cf. BRANDÃO, 1979, p. 18-19) a longas cenas de tiroteios, assaltos e ataques terroristas.

Vale ressaltar, nesse espaço de crise, o surgimento de uma geração de jovens violentos que em muito se assemelham a Alex e seus druguis em Laranja mecânica. Em visita à Filhoda, cidade de sua esposa, José é abordado por um grupo de jovens que, sem aparente motivo, resolvem hostilizá-lo:

? Por que vocês se preocupam comigo.

. Não gostamos de você. Por isso.

- Você tem 24 horas para deixar a cidade.

- Olha, você pode mandar nesses bostinhas dos teus amigos, em mim não.

- Mando em tudo. Eu e eles, nós fazemos o que nós queremos. Pra se divertir. Você é a nossa diversão.

- Vamos fazer como fizemos com aqueles comunistinhas da faculdade.

? Sabe o que fizemos.

- Batemos em todos. Um deles, um negrinho baixote, andava pregando reforma agrária. E nós fizemos uma reforma agrária nele. Pegamos ele e levamos pra fazenda do Diabo Loiro.
O governo, contudo, não vê a violência despropositada desses jovens como um problema, encontrando rapidamente uma forma de canalizá-la. Da mesma forma como alguns companheiros de Alex, em Laranja mecânica, acabam entrando para a polícia e passando a agir violentamente com legitimação institucional, em Zero, o governo recruta esses jovens para suas fileiras de repressores:

José mostrou. $\mathrm{O}$ soldado era quase moleque, cacetete (SIC) 50 centímetros na mão, metralhadora no ombro. A arma pesada, ele ficava curvado. Fazia cara de mau, gritava. (Deve se divertir)

. Vai, vai, VAI, VAI

Funcionava a Operação Patrulheiros do Norte. Rapazinhos em idade militar, orgulhosos de autoridade, cheios de poder, vaidosos com as metralhadoras, arrojados, impunes. Eles tinham atendido aos anúncios que prometiam armas, viaturas e prêmios pelas prisões (BRANDÃO, 1979, p. 146).

A militarização da juventude é, no entanto, apenas uma manifestação de um plano maior do governo para a integração da população na fiscalização e combate ao crime. Começa-se a se configurar, nesse momento, o clima de paranoia e vigilância que impera nas distopias, em que 


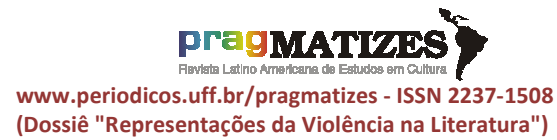

cada cidadão é um agente em potencial de fiscalização do governo:

O secretário da Segurança foi à televisão e pediu a colaboração do povo diante da onda de assaltos. "É preciso reagir, não ficar passivo, guardar a fisionomia dos bandidos, denunciar, ajudar a polícia a conter a onda de assaltos, prostituição, contrabando, tráfico de entorpecentes. Vamos fazer de cada cidadão um policial." (BRANDÃO, 1979, p. 100)

Uma das manifestações mais violentas e poderosas desse aparato civil de controle da criminalidade se dá na formação de um esquadrão da morte que vai ganhando poder e liberdade de ação ao longo da narrativa. É anunciada ainda no começo da obra, em um fragmento que indica seu surgimento como resposta à violência urbana:

A cidade se humaniza. Meninas curradas

em plena luz do dia. Ladrões assaltam mulheres

que saem às tardes para fazer compras.

Ladrões brigam com ladrões

e se matam, se assassinam.

Estaria sendo formado um

Esquadrão Punitivo.

Já tinha existido um, anos atrás. Nos tempos heróicos. (BRANDÃO, 1979, p. 49)

Explorando o descontentamento da população com os estupros e assaltos, como mencionado no trecho, esse Esquadrão Punitivo será prontamente exaltado pela população. Ao ter sua fama de assassinos espalhada, "deixara de ser a organização clandestina que matava e telefonava para os jornais informando o local. Depois da reportagem no Life tinha sede, carros especiais, uniformes cheios de galões, cromados, botas altas, quepes" (BRANDÃO, 1979, p. 116). Sua ação na obra, contudo, não é outra senão a de igualmente trabalhar na repressão das dissidências do governo, talvez de forma ainda mais violenta que a polícia comum.

Assim como o Esquadrão Punitivo, o governo explora o medo e a revolta do povo à situação de crise para consolidar sua própria forma de violência: política e cognitiva. Lembremos que o romance já não está no mesmo estágio de desenvolvimento do Estado distópico de Laranja mecânica, no qual o governo totalitário ainda buscava apoio nas vias democráticas. Em Zero, nos encontramos exatamente no passo seguinte: um governo totalitário recente, dando seus primeiros passos na consolidação do poder através de suas medidas autoritárias.

Dessa forma, ao longo da obra, temos fragmentos exclusivamente dedicados aos pronunciamentos do governo e a implementação de suas medidas, nas quais vemos, progressivamente, como os discursos e leis se tornam cada vez mais totalitários. O primeiro desses fragmentos, denominado "O tempora, o mores", em alusão ao discurso de Cícero nas Catilinárias sobre a depravação dos costumes e a corrupção de seu tempo, 


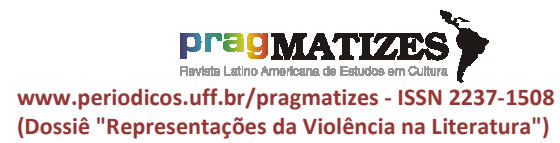

condensa, na voz do presidente, a mensagem de uma distopia em formação:

"Ou nos unimos, ou o mundo explode numa onda de desregramento, pecado, imoralidade." O Presidente falava numa praça da capital. Diante dele, milhares de pessoas, atentas. Cada uma trazia na mão uma tocha acesa e o Presidente tinha uma visão fantástica: um fogo que iluminava / mas para ele, o fogo consumia; naquela noite devia começar uma reforma nos costumes e nas leis/. Os microfones levavam a palavra do Presidente a todas as praças do país, a todas as casas. Abaixo do palanque havia um estrado, onde se sentavam os altos dignitários da Igreja, Ministros, Juízes dos Tribunais Superiores, ProcuradoresGerais, o Chefe Supremo das Milícias Repressivas, os Encarregados da Ordem e Moral, os Cruzados, os Templários, os Defensores das Famílias, os Vingadores. Cada um representava centenas de associações e ligas e organizações que estavam sendo formadas no país, em defesa dos bons costumes, da família, da boa conduta, da liberdade, da propriedade. Estas centenas representavam milhões de pessoas. "Vamos nos lançar numa grande campanha, num movimento monstro, para que a moda seja mais sóbria, para que as saias desçam aos tornozelos, para que as revistas licenciosas sejam queimadas, para que o palavrão deixe de existir em nossa amada e tão bonita língua, para que os jovens levem uma vida decente e recatada, para que 0 termo prostituição seja abolido de uma vez de nossa Pátria bemaventurada, para que não haja pílulas e todos procriemos muito para a grandeza futura. Para isso estamos mudando tudo, mudando nossas leis para proteger a sociedade, e portanto, proteger vocês. (BRANDĀO, 1979, p. 19. Grifos nossos)
A cena já remete a certa imagética consolidada das narrativas distópicas: o grande líder discursando, o povo abaixo, hostil, com suas tochas, sendo alimentado pelo ódio destilado. Outra imagem recorrente das distopias, graças a Fahrenheit 451,e que voltará a aparecer em Zero posteriormente, é a queima dos livros. Aqui, apenas revistas licenciosas, mas posteriormente outros tipos de livros também. Vale ressaltar ainda o uso de "movimento monstro" como caracterização para o projeto de mudança que é proposto, reforçado a caracterização monstruosa do governo nas narrativas distópicas. Por último, entrevemos na última frase a sugestão dessa virada em direção à distopia, cuja lógica de funcionamento difere plenamente daquela encontrada no presente. Para isso, seus dirigentes, a partir da justificativa de "proteger a sociedade" poderão mudar livremente o funcionamento das leis, costumes e ideias daquela comunidade.

O discurso, assim como toda a inclinação moral-religiosa do governo, poderia, muito bem, ser oferecido como um discurso de formação da Gilead de $O$ conto da aia. De fato, em uma das memórias de Offred apontando para o passado precursor da situação distópica vivida no romance, vemos a mesma queima de revistas licenciosas apontada no discurso do presidente de Zero:

Havia alguns homens, também, em meio às mulheres, e os livros eram 


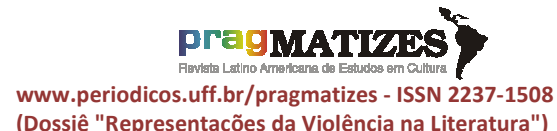

(Dossiê "Representações da Violência na Literatura")

amarrilhos e as cores permitidas são o marrom e o preto. (BRANDÃO, 1979, p. 86)

Não só vemos que o discurso deu lugar a proibições mais claras, como o controle do comportamento já se escala na previsão de prisão para mínimas manifestações afetivas. A quinta regra remete, ainda, à uniformização das roupas que também é imagem recorrente no imaginário distópico e será, posteriormente, plenamente concretizada.

Da mesma forma, o governo acaba com os espaços de entretenimento, alegando a necessidade de as pessoas ficarem em casa, com a família (p. 92); proíbe o uso do biquíni (p. 111); censura todas as músicas profanas, permitindo apenas músicas religiosas e marchas patrióticas (p. 141); controla a natalidade e impõe prisão perpétua ao aborto (p.160). Até atingir, em um dos fragmentos chamado "Temperatura instável, sujeira a chuvas e trovoadas" o clímax da violência em nome da moral cristã:

Começou o fuzilamento de prostitutas, ontem, às seis horas, nas principais capitais do país. Trata-se de uma campanha para exterminar o vício, comunicou o Ministério do Bem-Estar Social. Ao ser entrevistado, salientou que não é uma atitude desumana, porque todas as mulheres terão chance de regeneração e conversão. Se aceitarem, serão libertadas e irão trabalhar como enfermeiras e assistentes sociais. Deverão apenas se confessar e comungar uma vez por semana, sendo que o padre carimbará carteira que elas apresentarão cada três meses na 


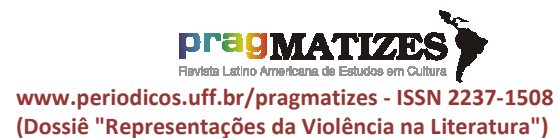

(Dossiê "Representações da Violência na Literatura") delegacia mais próxima, As que não aceitarem, serão fuziladas. A grande maioria não está aceitando. E assim, as putas morrem ao amanhecer. A lei que atinge as prostitutas é mais ampla: todo aquele que for apanhado em ato com uma delas, será preso e julgado. Sendo casado, será fuzilado, por se tratar de adultério. Sendo solteiro, apanhará de dez a vinte anos de prisão por vício (BRANDÃO, 1979, p. 148).

Não é, contudo, apenas nas imposições morais que o governo distópico em ascensão de Zero se assemelha aos encontrados nas distopias totalitárias canônicas. Outras duas fortes marcas distópicas, a coletividade compulsória e o controle da informação ${ }^{6}$, também aparecem em formação ao longo do romance de Brandão.

Uma das marcas mais explícitas dessa coletividade compulsória - marca muito ligada à própria estética distópica, condensando na imagem do espaço e na caracterização dos personagens a padronização - é a uniformização e separação por classes:

Determinaram as cores. Por categorias sociais. Os ricos usariam vermelho, azul, rosa, lilás, vinho, bordo e todas as variações em torno. As variações seriam escolhidas pelo computador, de acordo com o imposto de renda. Depois viriam os menos ricos, a classe média alta, a baixa, as classes mais baixas,

\footnotetext{
${ }^{6}$ Assim como o controle da moral, tais características não são distópicas, mas próprias de muitos governos totalitários reais, pode-se argumentar. E, no entanto, na forma satírica e magnificada - que tais elementos são apresentados ao leitor que reside seu o potencial distópico.
}

surgindo o amarelo, o laranja, o abóbora, e todas as variações, e o azul, o verde, o marrom, terminando no preto que era a cor dos que não tinham nada, nada, nada. Além das casas, o decreto incluía também as roupas com modelos desenhados pelos especialistas e que variavam entre um uniforme militar e um terno Mao, em brim, para o verão e em lã para o inverno. Havia apenas dois tipos de desenhos e nenhuma possibilidade de escolha (BRANDÃO, 1979, p. 89-90).

As cores marcavam tanto as casas de cada classe - casas cujas "plantas são iguais. Sem diferença. Trezentas páginas, cada página dez plantas. Iguaisinhas" ( $p$. 130) - quanto os uniformes vestidos por eles - como em $O$ conto da aia, em que cada classe tem um uniforme e uma cor atribuída a ela, dividindo Gilead em aias, esposas, Martas, tias e guardiões. Se, nas distopias plenas, tal divisão já é plenamente integrada à lógica de mundo daquela sociedade - muitas vezes determinada já no nascimento, como a preparação biológica das classes em Admirável mundo novo -, em Zero a medida ainda dá seus primeiros passos. Não chegamos a ver a efetiva divisão por cores anunciada, pois, no presente da obra, o governo ainda começa a se organizar para tornar a proposta realidade:

Já se encontram em todas as boas lojas do ramo os uniformes para o povo, nas cores estabelecidas pelo governo, de acordo com as classes sociais e profissões. Os uniformes são baratos, acessíveis. Os que não puderem comprá-los à vista, poderão fazê-lo a prazo, através das Caixas, 


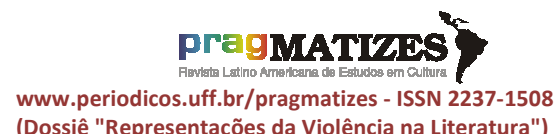

(Dossiê "Representações da Violência na Literatura") com financiamento do governo. Para isso, basta levar: Escritura da casa, Contas de luz e gás, Carteira Profissional, Identidade, Quitação com a Hora Oficial, Atestado de Residência, Boa Conduta, Antecedentes, Salvo Conduto, Carnês de Compras a Crédito. Dentro de dois meses, o povo todo deverá estar uniformizado (BRANDÃO, 1979, p. 191).

O mesmo pode ser dito em relação ao controle da informação. Longe de ter um aparato de vigilância e propaganda eficazmente instalado como vemos nas teletelas de 1984, o governo de Zero dá seus passos iniciais nessa direção. Uma das primeiras medidas, claro, é a censura. Vemos, desde o começo da obra, a menção a editoras fechadas. A queima de revistas licenciosas que anteriormente mencionamos evolui para uma prática corriqueira em que se dá, "todas as noites, nas praças principais de todas as cidades, a queima de livros ao som de hinos religiosos" (BRANDÃO, 1979, p. 157). A prisão de estudantes também é recorrente ao longo da obra (p. 19), junto com a fuga de intelectuais perseguidos, representada ao longo de toda a obra através dos fragmentos denominados "Adeus, adeus".

Em relação à propaganda, se não há a ubiquidade das teletelas, já encontramos a difusão obrigatória de informação do governo através da instalação de alto-falantes:

José, contemple a colocação desses alto-falantes. De hoje em diante, eles vão transmitir os ditos do seu governo. E todos ouvirão. Não será possível desligar, José, como todo mundo fazia, das sete às oito. Agora, esses alto-falantes, em altapotência, falarão e o povo ouvirá, nem que ponha algodão, cera, tapa-ouvidos. Saiba, José, que eles estão instalados em todas as cidades, até nas vilas de duas e três casas. Serão instalados nas tabas dos índios, onde haja índios, onde houver índios, nesta terra.

José se prepare.

Locutores de vozes monótonas e graves discorrerão sobre os atos do governo, que você terá a cumprir amanhã.

Saiba, José, que os cinemas vão parar nessa hora, as igrejas, teatros, televisões.

His Master's Voice

Marque: vamos conferir nossos relógios, José:

Às oito (BRANDÃO, 1979, p. 63).

Não é, porém, o caráter ainda provisório dessas medidas a maior característica desse estágio anterior de formação do um Estado distópico, mas a presença de uma resistência social que se vê eliminada ${ }^{7}$ nas distopias plenamente estabelecidas. É justamente contra essa resistência que vemos se impor de forma mais direta a violência que marca a ruptura com a organização de mundo prédistópica. Se nas medidas anteriores,

\footnotetext{
${ }^{7}$ Em obras como Nós e O conto da aia, vemos uma organização revolucionária. No entanto, nas distopias plenamente estabelecidas, esse grupo não age abertamente e é desconhecido ou odiado pela população de forma geral. Não há espaço para descontentamento popular e para manifestações, e também não há um confronto direto, mas um embate subterrâneo, bem distinto da perseguição aberta e da resistência de uma parcela da população que vemos ainda nesse estágio de formação do Estado distópico, em obras como Laranja mecânica, Zero e Years and Years.
} 
temos majoritariamente uma violência política - de eliminação de direitos - e cognitiva - de mudança drástica de visão de mundo -, a violência direta, física, será utilizada em ampla escala contra aqueles que se opõem diretamente ao governo.

Em Zero, a brutalidade policial que é exposta desde o começo da narrativa vai se intensificando conforme José se associa com os Comuns, grupo revolucionário caçado pelo governo. Bem antes de se envolver com os dissidentes, no entanto, já sofre a violência da polícia quando é convocado para depor sobre o caso de um assaltante de bancos supostamente ligado aos Comuns que mora na mesma pensão que ele. Mesmo sem nenhuma conexão direta com o caso, os policiais não hesitam em torturá-lo:

. Não sei de nada, não conhecia ele. Ele morava lá no quarto dele, eu no meu, a gente nem se encontrava. . Tinha seu nome numa lista. . Não sei de nada juro.

- Acho que você precisa é apanhar mais.

O tira bateu em José durante cinco minutos.

O tira bateu em José durante cinco minutos.

O tira bateu em José durante cinco minutos.

Deram amoníaco para José cheirar. Ele acordou.

. Se não dé esse serviço logo, vai ficá aqui muito tempo.

. Então, vou ficar, porque não sei de nada. (...) (BRANDÃO, 1979, p. 47)

O nível de brutalidade escala conforme o governo avança em suas medidas e os Comuns resistem. José, cansado das arbitrariedades do governo - e daquela sociedade como um todo começa a assassinar pessoas para descontar seu descontentamento, sobretudo contra os militares. Gê, líder dos Comuns, percebendo a eficácia de José em seu passatempo, não demora a recrutá-lo para a fileira dos revolucionários, convite que José reluta em aceitar por não compartilhar os ideais do grupo. Uma vez convencido, passa a matar em nome do grupo, ainda que nunca se sinta plenamente parte dele.

Assim, vemos, por um lado, a violência dos Comuns e do público em geral, e, por outro, a resposta do governo, com seus grupos de extermínio, caçando o grupo a qualquer custo. As cenas mais explícitas dessa violência se dão nas cenas de tortura dos capturados pelo governo. Nos últimos fragmentos do livro, se avultam os trechos dedicados a uma descrição detalhada dos atos dos torturadores - ocupando até diversas páginas, como na tortura de um dos amigos de José, Átila. É, no entanto, no relato sobre Crato, supostamente um Comum que dividiu sua cela com um membro do grupo de José, que temos o mais chocante exemplo da violência absurda desse estado totalitário:

Tiravam ele da cela, à noite, ele voltava de manhã, sem dentes, ensanguentado. Não podia andar, tinha as solas dos pés em carne viva. Picada de agulhas. Não dava o serviço, eu sabia que iam matar ele, mas o cara não dava serviço. Passava o dia na cela, apavorado 
com o que viria à noite. Cada dia, inventavam uma. Inventavam não. Aplicavam. Eram profissionais. (...) Um dia, levaram o sujeito pro pau de arara. "Dá o serviço: nomes, aparelhos, planos. Dá, que é tua última chance." O interrogador tinha as mãos postas, e suplicava. O Crato, quieto, nu, dependurado, os fios elétricos no saco. O saco, o pinto, a bunda, tudo dele era carne viva. Passaram navalha no corpo dele, fizeram cortes finos como fios de cabelo, o sangue brotou. Jogaram salmoura, depois água gelada. $\mathrm{O}$ interrogador chorava: "Pelo amor de Deus, eu tenho dó, não quero fazer isso. Seja bom comigo, não faça uma coisa dessas, você não tem direito." Trouxeram para a sala, a mulher e os três filhos do sujeito. $\mathrm{O}$ mais novo tinha quatro meses. "Diz, nomes, aparelhos, planos." Crato, quieto. Nem podia falar, não tinha língua. Tiraram a roupa da mulher dele. Comeram ela, ali. Seis caras marrudos. Enrabaram, gozaram na cara dela, bateram. "Diz, vai dizer, agora vai." Crato não disse, ligaram todos os fios possíveis, na orelha, nariz, dentro da boca, dedos, enfiaram no canal da uretra. Estavam encapetados, gritavam, como quem goza numa mulher. Pegaram o menino de quatro meses, deram um choque, o menino chorou. Deram outro, o menino morreu, pretinho. A mulher gritou, enlouqueceu naquela hora mesmo. "Nós matamos sua família e você não diz nada. É mesmo filhodaputa." Bateram nos outros filhos. Então, ligaram os fios. Eletrocutaram Crato. Nem que tivesse passado num fio de alta tensão. Quase se desintegrou. Sumiram com a mulher, com os filhos, com tudo." (BRANDÃO, 1979, p. 255-6)

Assim como podemos entrever, em Laranja mecânica, a ascensão do Estado distópico que se esboça ao longo da narrativa, Zero conclui oferecendo uma imagem semelhante em seu horizonte. Os
Comuns vão sendo capturados, torturados

e fuzilados, até que José é pego e, passando pelo mesmo processo, sua história se encerra no fragmento "Granfinale", diante do pelotão de fuzilamento. Nesse ponto da narrativa, José, após uma insuportável dose de sofrimento, já está alucinando, o que é refletido na linguagem caótica do fragmento, deixando apenas entrever os últimos pensamentos do protagonista de Zero antes de sua morte:

José, Joe, Josepho, José viu (ouviu): o céu coberto. Trancado. Uma placa, incandescente. Fechado. (Irremediavelmente) Pôr uma tampa. A placa formou uma bola. E O mundo, encerrado dentro. A placa: milhões de projéteis: balas de canhão-revólver-fuzil-

metralhadoraespingarda-foguete-

bazuca, E ele ouviu o ruído (ensurdecedor) e o eco do ruído por dentro da bola de fogo: motores, aviões, carros blindados, caminhões, tanques, explosões, ordens de comando, ordem unida / apontarfogo-fuzilamento/, gritos de dor e alegria e gargalhadas e botas. E José, Joe, Josepho, José viu refletido no ferro incandescente (tela, vídeo, tv, vidro) a nova ordem, os grilhões, a nudez (finalmente, todas as palavra proibidas), a imobilidade (finalmente, todos os gestos interditados), os comuns fuzilados, Gê crucificado (mas Gê, eu me lembro, tinha fugido, escondido, criava galinhas numa granja, vendia ovos, estercos, pintos de um dia). ? Será que pegaram Gê (de novo), pegaram todos, vão continuar a pegar até que possa descobrir um modo de lutar e organizar. E então, inverter. E reinverter. Quem está certo, estará errado, quem está errado, estará certo, quem depois estiver errado hoje-certo-incerto e quem estiver certo-errado, depois certo ou errado. E a placa mais 
quente, a bola de fogo. A terra fechada dentro e a bola disparada. (BRANDÃO, 1979, p. 284)

Em sua alucinação, José vê como reflexo de sua morte "os comuns fuzilados" e "Gê crucificado", permitindo, então, a ascensão dessa "nova ordem" que se forma com a consolidação do Estado distópico. Sem mais resistência aberta, a população pode ser controlada, a história pode ser reescrita e a violência fundadora pode ser devidamente apagada, nos conduzindo diretamente à distopia plena de Não verás país nenhum.

\section{Considerações finais}

É importante ressaltar que essa leitura de Zero, uma leitura, voltamos a frisar, à revelia das análises mais tradicionais, só é possível em uma determinada organização do quebracabeça de fragmentos que o livro apresenta. Separando as narrativas mais sóbrias sobre a trajetória de José e os comentários sobre o governo e a sociedade, conseguimos construir, num ato interpretativo, esse Zero pré-distópico aqui apresentado.

Para tal, foi necessário negligenciar diversos fragmentos que apontam para direções diferentes. Algumas delas ainda serviriam para reforçar nossa mensagem, mas nos levariam a uma digressão demasiado longa de nosso objetivo central, como a colonização americana, o consumismo exacerbado e as doenças e deformações, todos temas que ecoarão posteriormente na formação da São Paulo distópica de Não verás país nenhum. Outros temas, contudo, acabam afastando Zero de uma caracterização mais solidamente distópica, sobretudo aqueles em que o absurdo toma o primeiro plano.

Alinhados aqui ao pensamento de autores como Darko Suvin (1979, p. viii) e Gregory Claeys (2010, p. 109), acreditamos que é parte da expectativa de leitura das distopias stricto sensu a plausibilidade da narrativa apresentada, ou seja, ainda que apresente uma visão distorcida, magnificada, satírica e negativa do presente de produção, essa visão ainda precisa - mesmo que apenas dentro do pacto ficcional - ser vista como a predição de um futuro possível para o presente de seu contexto de produção ${ }^{8}$.

Ao explorar o surrealismo e o absurdo em certos fragmentos, Zero abala a possibilidade dessa plausibilidade. Caso fosse uma narrativa linear, uma leitura como a aqui feita se veria bastante fragilizada por tal característica. No entanto, ao optar pelo fragmento, Zero nos convida a jogar com suas cenas,

\footnotetext{
${ }^{8}$ Sabemos, no entanto, que tal posicionamento, construindo uma visão mais restrita de distopia, não encontra consenso na crítica especializada, havendo aqueles que não vejam esse maior grau de realismo como uma necessidade inerente ao enquadramento no gênero.
} 
permitindo organizar um caminho de leitura que torna essa visão de distopia possível $^{9}$.

Ainda que todos os romances canonizados no gênero distópico apresentem esse Estado plenamente estabelecido do governo totalitário, tomar esse estágio como fronteira para a definição do gênero nos impediria de trabalhar com obras que claramente estão relacionadas com o gênero, sem necessariamente se encaixarem nos moldes de Nós, Admirável mundo novo ou 1984. Como vimos no caso de Loyola, o próprio autor nega, talvez por tomar como distopia essa visão mais restrita do gênero, o enquadramento de Zero como tal, ainda que, como esperamos haver conseguido mostrar ao longo deste artigo, a obra, em sua hipérbole satírica da crise de seu contexto de produção e das medidas autoritárias do período ditatorial, se apresente até mais distópica que o romance de Burgess - este mais comumente relacionado com o gênero.

Enquanto muitos tomam Nóscomo um ponto de partida para o gênero distópico - ou mesmo The Machine Stops [1909], de E. M. Forster -, observando

\footnotetext{
${ }^{9} \mathrm{O}$ mesmo talvez já não se possa dizer de Desta terra..., em que a opção pelo absurdo não se dá em fragmentos isolados, mas é parte integrante da construção da sociedade imaginada por Brandão. Oferecido como distopia, seu exagero é tal que a plausibilidade se perde, tornando a alegoria a única possibilidade de leitura daquela sociedade imaginada.
}

apenas as obras em que já há plenamente estabelecida essa drástica ruptura com a lógica de funcionamento do mundo contemporâneo, Jack London, em 1907, já produzia Tacão de ferro, uma obra que se entendermos como parte do gênero essas obras situadas não no cume, mas na ascensão do Estado distópico -, projeta, assim como Zero e Laranja mecânica, em um futuro não muito distante a formação de um Estado distópico dominado pelos grandes conglomerados capitalistas à custa de um massacre do proletariado socialista que ganhava força no momento.

Através de um estudo desses diversos estágios de formação de uma distopia, podemos não apenas reler obras até então afastadas do gênero - ou vistas como exemplos divergentes -, mas afinar nossa leitura dos próprios romances distópicos canônicos, em que a violência fundadora é escondida, mas existente. Podemos, ainda, ressaltar os efeitos buscados em cada estágio desse progresso, em que uma maior proximidade com o contexto de produção diminuiria esse estranhamento (cf. SUVIN, 1979, p. 6; BOOKER, 1994, p. 19) explorado pela distopia plena para fazer sua crítica ao presente, mas, ao mesmo tempo, ressaltaria que o caminho até esse cenário é bem mais curto do que se pode entrever nas obras canônicas. 


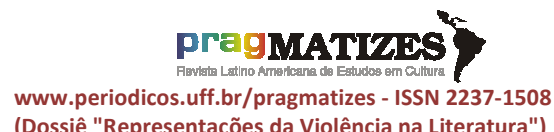

(Dossiê "Representações da Violência na Literatura")
Começamos este artigo mostrando o retorno das distopias totalitárias ao pensamento contemporâneo. Mas trabalhamos com uma obra do período da ditadura militar no Brasil. Aparente descompasso, essa escolha, no entanto, se dá pela importância de entender como uma obra como Zero pode dialogar com a produção distópica contemporânea e como sua análise pode nos dar ferramentas para trabalhar com aquilo que se está produzindo hoje. Em um momento político como o que vivemos atualmente, é compreensível que Years and Years opte por mostrar não a distopia plena, mas seu processo de formação. Fenômeno

\section{Referências bibliográficas}

ATWOOD, Margaret. O conto da aia. Trad. Ana Deiró. Rio de Janeiro: Rocco, 2017.

BOOKER, Keith M. The dystopian impulse in modern literature: fiction as social criticism. London: Greenwood Press, 1994.

BRANDÃO, Ignácio de Loyola. Zero. $3^{\text {a }}$ ed. Rio de Janeiro: Ed. Codecri, 1979.

BURGESS, Anthony. Laranja mecânica. Trad. Fábio Fernandes. São Paulo: Aleph, 2014.

CLAEYS, Gregory. The Origins of Dystopia: Wells, Huxley and Orwell. In: The Cambridge Companion to Utopian Literature. Cambridge: Cambridge University Press, 2010. p.107-131.

CLAEYS, Gregory. Dystopia: a Natural History. Oxford: Oxford University Press, 2017. semelhante pode ser encontrado na escolha da adaptação televisa de $O$ conto da aia de explorar, nos flashbacks, esse período de transição entre democracia e totalitarismo de forma mais aprofundada. Em ambos os casos, se tenta refletir não sobre os perigos de um Estado totalitário plenamente estabelecido, cuja ameaça ainda não se tenha conformado plenamente em nosso horizonte de expectativa, mas sobre a fragilidade da democracia e a rapidez e facilidade com que um governo autoritário pode, à custa de muitas vidas, mudar drasticamente 0 rumo de uma nação.

OLIVAS, Daniel A. The Dystopia Is Here. The New York Times, 19 junho 2018. Disponível em: https://www.nytimes.com/2018/06/19/o pinion/children-separated-fromparents-border-immigrantdystopia.html. Acesso: 21mar. 2019.

ORWELL, George. 1984. Trad. Alexandre Hubner, Heloisa Jahn. São Paulo: Companhia das Letras, 2009.

SUVIN, Darko. Metamorphoses of Science Fiction: on the Poetics and History of a Literary Genre. New Haven e London: Yale University Press, 1979.

VIEIRA, Fátima. The Conceptof Utopia. In: CLAEYS, Gregory (org.). The Cambridge Companion to Utopian Literature. Cambridge: Cambridge University Press, 2010. p. 3 - 27. 